\title{
Bystander Memory T Cells and IMiD/Checkpoint Therapy in Multiple Myeloma: A Dangerous Tango?
}

\author{
Anne Marit Sponaas ${ }^{1 *}$, Anders Waage ${ }^{1,2}$, Esten N. Vandsemb ${ }^{1}$, Kristine Misund ${ }^{1}$, \\ Magne Børset ${ }^{1,3}$, Anders Sundan ${ }^{1}$, Tobias Schmidt Slørdahl ${ }^{1,2}$ and Therese Standal ${ }^{1,4}$ \\ ${ }^{1}$ Department of Clinical and Molecular Medicine, Center for Myeloma Research, Faculty of Medicine and Health Sciences, \\ Norwegian University of Science and Technology (NTNU), Trondheim, Norway, ${ }^{2}$ Department of Hematology, St.Olavs \\ Hospital, Trondheim, Norway, ${ }^{3}$ Department of Immunology and Transfusion Medicine, St.Olavs Hospital, Trondheim, Norway, \\ ${ }^{4}$ Department of Clinical and Molecular Medicine, Center of Molecular Inflammation Research, Faculty of Medicine and Health \\ Sciences, Norwegian University of Science and Technology (NTNU), Trondheim, Norway
}

In this review article we discuss the role of the memory $T$ cells in multiple myeloma (MM) and how they may influence immune responses in patients that received immunomodulating drugs and check point therapy.

Keywords: multiple myeloma, T cells, checkpoint therapy, immunomodulating drugs, virus

\section{INTRODUCTION}

\section{OPEN ACCESS}

Edited by:

Nurit Hollander,

Tel Aviv University, Israe

Reviewed by:

Paola Neri,

University of Calgary, Canada

Douglas Edgar Joshua

The University of Sydney, Australia

*Correspondence:

Anne Marit Sponaas

anne-marit.sponaas@ntnu.no

Specialty section

This article was submitted to Cancer Immunity and Immunotherapy,

a section of the journa

Frontiers in Immunology

Received: 01 December 2020 Accepted: 26 January 2021

Published: 15 February 2021

Citation:

Sponaas AM, Waage $A$ Vandsemb EN, Misund K, Børset M, Sundan A, Slørdahl TS and Standal T (2021) Bystander Memory T Cells and IMiD/Checkpoint Therapy in Multiple Myeloma: A Dangerous Tango?

Front. Immunol. 12:636375 doi: 10.3389/fimmu.2021.636375
Checkpoint therapies with anti-PD1/PDL1 have been successful in malignant melanoma and lung cancer. In MM however, monotherapies with-anti PD1 were not effective. Initially, combining anti PD1 with immunomodulating drugs (IMiDs) demonstrated acceptable toxicity and objective overall response in $44 \%$ of patients in a phase I/II clinical study (1). However, when tested in 2 phase III clinical trials, Keynote 183 and 185, there were more deaths in the checkpoint arm and the studies were terminated $(2,3)$. This led to the termination of many other clinical studies involving PD1/PDL1. Understandably, there has been some reluctance in revisiting PD1/PDL1 therapy in MM. However, we do not yet fully understand why PD1/PDL1 treatment failed and why some patients suffered fatal side effects. In this review we will discuss how $\mathrm{T}$ cells could be involved in adverse effects and failure of PD1 therapy.

\section{IMMUNE RESPONSES IN MM PATIENTS}

$\mathrm{T}$ cells control and remove MM after recognition of tumor specific or tumor associated antigen (TAA). This happens directly by CD8 T cells killing the tumor cells or indirectly by activating NK cells or macrophages after cytokine release such as IFNg (4). Conversion from MGUS and Smoldering Multiple Myeloma (SMM) to MM is characterized by changes in the immune cells in the bone marrow (BM). This includes an alteration in the myeloid cell populations in the bone marrow such as a reduction in the ability of DC to stimulate T cells, switch from M1 to M2 macrophages and increase in immunosuppressive Myeloid Derived Suppressor Cells (MDSC) reviewed in Guillerey et al. (4). There is also evidence that cells in the BM interact to induce an immunosuppressive environment, for example BM-derived IL18 will generate MDSC that suppress CD8 T cell responses in mice and was associated with poor survival in humans (5). There is also a change in $\mathrm{T}$ cell phenotype. This is associated with a decrease of $\mathrm{T}$ effector functions such as cytotoxicity and IFN $\gamma$ and an increase in surface expression of many exhaustion markers including PD1, TIGIT, LAG3 and changes in transcription factors such as Eomes and TCF1 (6-8).Interestingly, anti TIGIT antibodies reactivate exhausted T cells and reduce tumor load in a mouse model of MM (8). 
Expansion of CD8 T cell clones have been observed in MM patients and were associated with improved survival, and interestingly, these clones expanded after treatment with IMiDs (9) Myeloma patients also have senescent and senescent like KRLG1+, CD57+, CD160+, CD28-, CD8 T cells. Whilst the senescent-like $\mathrm{T}$ cells have normal telomere-length and can produce some inflammatory cytokines, the senescent $\mathrm{T}$ cells have short telomers and are nonfunctional (10). These cells do not express PD1 and are unable to respond to anti PD1 check point therapy and this was suggested to be a reason for the failure of response to anti PD1 in MM patients (10-12). There is an increase in Treg cells in the tumor microenvironment (TME) in the bone marrow (BM) of patients which is associated with poor outcome and early relapse (13-15). Many of them have an activated phenotype and are directly promoting MM cell growth $(14,15)$. However, MM is also characterized by an inflammatory $\mathrm{T}$ cell response with elevated levels of Th17 (16), and IL32 activity $(17,18)$, and increased numbers of T effector cells (TEMRAs) $(17,19)$. Thus, the immune milieu in the BM in myeloma patients can both be inflammatory and immune suppressive, leading to thwarted immune responses to the tumor and pathogens, yet promoting an inflammatory environment that could generate osteoclast activity and bone lesions (20-22). Hypogammaglobulinemia is associated with $\mathrm{MM}$ and increases the susceptibility to infections, as will immune suppression and hyper-inflammatory environment. Reduced response to infections contributes to significant comorbidities for MM patients who has 7-fold increase in contracting bacterial and a 10-fold increase in developing viral infections compared with age-matched controls (23). Modern treatment can also modulate immune cells and new therapies have led to increased rates of bacterial, viral and fungal infections (24). However, most MM patients can mount a $\mathrm{T}$ cell response that generate some protection against infections.

\section{T CELLS IN MM BONE MARROW}

There are different populations of $\mathrm{T}$ memory cells (Tmem), some are circulating and others resident in the TME. These are characterized by different surface markers and transcription factors. In this paper we are focusing on CD8 T cells as these are important for anti-tumor activity. This is not to say that $\mathrm{CD} 4 \mathrm{~T}$ cells are unimportant. Although reduced in some $\mathrm{MM}$ patients, $\mathrm{CD} 8+\mathrm{T}$ central memory (Tcm) (CD45RA-,CD45RO+,CCR7+), T effector memory (Tem) (CD45RA+,CD45RO+,CCR7-) as well as T resident memory (Trm) (CD45RA-,CD45RO+,CD103+,CD69+) are found in the bone marrow $(17,19,25)$. In addition to the markers above, memory cells also express certain transcription factors whose expression may vary according to the degree of activation and the milieu in the TME. For example, T mem cells from MGUS patients will have higher expression of stemness marker TCF1 and less Eomes and Tbet compared with T mem from myeloma patients (17). Some of these cells recognize known tumor antigens such as Germline-Associated Antigens (GAAs,) tumor associated antigens (TAAs) or neo antigens (26-29). T memory cells from bone marrow of MM were also found to kill autologous myeloma cells (25). However, common to what is found in solid tumors where neoantigen-specific $\mathrm{T}$ cells contribute $<0.5 \%$ of CD8 $\mathrm{T}$ cells (30), the proportion of tumor-specific or TAA T cells in the bone marrow may also be relatively small. Indeed, memory T cells with non-tumor-specificities are found in the BM TME (19). This is not surprising as the human bone marrow is a reservoir for memory $\mathrm{T}$ cells against previous infections (31).

\section{MEMORY T CELLS AGAINST INFECTIOUS AGENTS}

Long-term immunity to pathogens is maintained by circulating and resident $\mathrm{T}$ and $\mathrm{B}$ cells. With the median time of diagnosis at 70 years, $\mathrm{MM}$ is more common in elderly people. People above the age of 60 have a reduced bone marrow output with fewer and less efficient hematopoietic stem cells (HSC) compared with younger people. Hematopoiesis is also skewed in a myeloid direction with lower lymphoid output as well as reduced TCR diversities. Many elderly people will also have more innate and adaptive immune cells with inflammatory phenotypes (32). A large proportion of our $\mathrm{T}$ memory cells will be against common latent and recurrent viral infections. About 90-95\% of people world-wide have been infected with and carry the Epstein-Barr virus (EBV) (33). Likewise, up to $90 \%$ of humans are seropositive for Cytomegalo virus (CMV) (34). Other latent virus infections like Herpes simplex virus (HSV-1) also generate long-lived T memory responses.

CMV has lytic and latent stages. Once the host is infected, CMV will remain causing recurrent latency and reactivation (34). Healthy individuals do not have long-term problems, but CMV can have serious consequences for immunocompromised patients. Infection generates high frequencies of CMV-specific CD4 and CD8 T memory cells. Control of CMV requires an active adaptive immune response where the CD8 $\mathrm{T}$ cells are crucial. The pool of CMV-specific memory $\mathrm{T}$ cells increase with age and can be up to $40 \%$ of the total memory $\mathrm{T}$ cell population. It is often oligoclonal and characterized by the presence of many senescent CD28-CD57+ and terminally differentiated CD45RA+CD45RO- TEMRAs with reduced functionality (35). In addition to providing a poor immune response to the CMV itself, the presence of these expanded, often terminally differentiated and senescent $T$ cells could by their large numbers diminish immune responses to pathogens and vaccines (36) or possibly even to cancers (37). In addition, most myeloma patients below the age of 70 will undergo autologous bone marrow transplantations (ASCT) as part of the therapy. This may reactivate $\mathrm{CMV}$ infection (38) and thus generate new anti-CMV $\mathrm{T}$ cell responses.

Most EBV infections are asymptomatic, but they can develop into infectious mononucleosis (IM) that will resolve in adolescents. The infection is first lytic releasing virus particles, and then enters a growth transforming latency program in B cells. The infection is characterized by sequential expression of viral genes recognized by CD8 and CD4 T cells. In some of the latent infected $\mathrm{B}$ cells the virus gene expression will be turned 


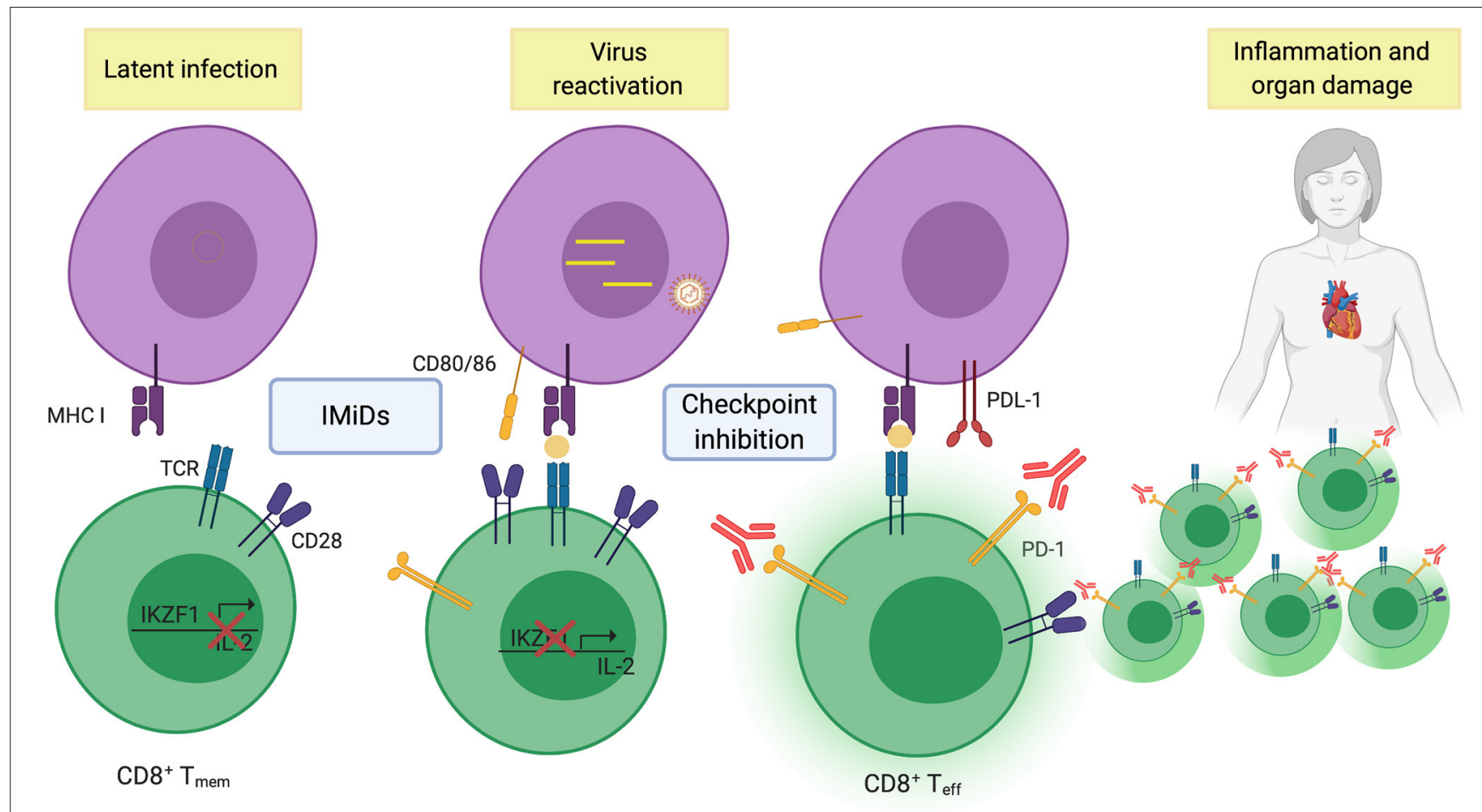

FIGURE 1 | Illustrating re-activation of effector T-cells to viral antigens after combined IMiD and checkpoint therapy. (Created with BioRender.com).

off avoiding immune responses. Similar to CMV, EBV can be reactivated at a later stage. The primary symptomatic infection is characterized by a massive expansion where up to $50 \%$ of all CD8 $\mathrm{T}$ cells are specific to viral proteins (39-41). After acute infection about $2 \%$ of the CD8+ memory cell pool will consist of cells specific to lytic antigens, and about $0.5 \%$ will recognize latent antigens (41). This relatively high frequency of EBV-specific CD8 memory cells can be found decades after the primary infection (42). Interestingly, the specificity of these virus -specific $\mathrm{T}$ cell clones (in terms of CDR sequence of the TCR) is remarkably stable over time including after lymphodepletion with cytostatic drugs (43). EBV specific T cells can also be detected in patients after bone marrow transplantation, including autologous stem cell therapy (ASCT) where they can be transferred during infusion of stem cells $(44,45)$ and/or generated after reactivation of virus (46).

CD8 $\mathrm{T}$ cells against various EBV, CMV, and influenza epitopes were found among TILs in lung and colon cancer biopsies $(30,47)$. These cells expressed markers of $\mathrm{T}$ resident memory cells (Trms-CD45RO+CCR7-CD103+CD69+) as well as PD1. Interestingly, they were more abundant in the tumor than tumor neoantigen- and TAA-specific T cells. The virus-specific CD8 T cells expressed similar levels of activation and inhibitory molecules as the tumor-specific $\mathrm{T}$ cells except from CD39 (30). CD39 is an exoenzyme involved in the generation of immunosuppressive adenosine in cancers such as MM (48).

\section{BYSTANDER T CELLS IN CANCER AND IMMUNOTHERAPY}

Bystander responses take place when $\mathrm{T}$ cells are activated independent of their antigen specific TCR or by cross reactive antigens. This can happen several ways:

Molecular mimicking of antigenic epitopes can activate $\mathrm{T}$ cells with cross-reactive TCRs. This has been described after infections with for example Streptococcus pneumonia and Borrelia burgdorferi where the pathogen induces $\mathrm{T}$ cell responses cross-reactive to self-antigens (49). Such responses have been linked to multiple sclerosis and cardiomyopathy $(50,51)$.

Allelic exclusion of TCR $\alpha$ chain during VDJ recombination is sometimes incomplete. This can lead to generation of $\mathbf{T}$ cells expressing 2 TCRs with different specificities. Indeed, up to 33\% of human $\mathrm{T}$ cells can have 2 functional $\alpha$ chains (52). Activation of $\mathrm{T}$ cells with dual receptors has been implicated in several models of autoimmune disease [reviewed in (53)].

Super-antigens such as bacterial endotoxins can also nonspecifically engage $T$ cells with different V $\beta$ TCRs leading to release of inflammatory cytokines and induction of selfreactivity (54).

Finally, T cells express innate and innate-like receptors. TLR2 and TLR4 engagement with lipoproteins or LPS can activate T cells non-specifically (55). TLR2 is expressed on memory T cells and there are reports of TLR2-mediated stimulation of EBVspecific memory cells leading to improvement of the anti-EBV 
response (56). TLR8, TLR7, and TLR9 have also been detected on $\mathrm{T}$ cells and could be involved in generation of bystander effects (57). For example, increased numbers of activated TILs were found in cutaneous melanomas after direct application of the TLR7 agonist imiquimod (58). NKG2D is an activating receptor on NK and T cells. This receptor binds non-classical MHClike ligands such as MHC class I polypeptide-related sequence A (MICA) and heat shock protein 60 that can stimulate T cells (53). NKG2D activation is augmented in the presence of cytokines such as IL-2, IL-7, and IL-15 (59-61). NKG2D engagement on CD8 memory $\mathrm{T}$ cells can also circumvent the need for CD4 T cell help, thus lowering the threshold for CD8 T cell activation.

Activation of bystander $\mathrm{T}$ cells will also depend on the presence of factors such as cytokines within the local environment. Memory $\mathrm{T}$ cells are more likely to become bystander cells than naïve $\mathrm{T}$ cells as they express higher levels of cytokine receptors (62) and can for example respond to elevated levels of IL-12, IL-15, and IL-18 present at high levels particularly during bacterial infections [reviewed in (53)].

\section{CHECKPOINT THERAPIES AND IMMUNE-RELATED ADVERSE EFFECTS}

Check point therapy with anti-CTLA4 will lower the threshold for initiation of immune responses as well as inhibiting Treg activities, and anti-PD1/PDL1 reactivates exhausted immune responses. However, reactivation of exhausted $\mathrm{T}$ cells may not be the only way checkpoint therapies work. Clonal expansion of non-exhausted, tumor reactive effector $\mathrm{T}$ cells (63) or recruitment and differentiation of stem cell-like memory cells (64) are also responsible for tumor regressions during treatment.

In recent years it has become clear that checkpoint therapies can cause IRAE in some patients. Both anti-CTLA4 (ipilimumab) and anti-PD1 (pembrolizumab, nivolumab) can elicit IRAE, antiCTLA4 tend to give more severe effects. The most common IRAEs will affect the gastrointestinal tract, liver, endocrine glands and skin leading to for example colitis, thyroiditis, hepatitis and vitiligo. However, although less common, cardiovascular, pulmonary, hematological and nervous system organs can be involved. Some of these IREAs can lead to serious complications and even death. Several cases of fatal fulminant myocarditis with $\mathrm{T}$ cell infiltration has been reported in patients treated with checkpoint therapies (65). Indeed, with a relatively high incidence of $0.6-1 \%$, cardiologists recommend a thorough cardiac assessment before commencing treatment (66).

The exact mechanism behind the IRAEs is not fully elucidated, but it is reasonable to hypothesize that activation of quiescent, self-reactive $\mathrm{T}$ cells would be involved.

Studies in mouse models have shown that PD1-/- mice develop autoimmunity including cardiomyopathy (67) and antiPD1/PDL1 treatment can activate anergic auto-immune T cells inducing organ damage (68). Memory $\mathrm{T}$ cells reactive to pathogens could also be culprits and be activated as bystander cells to generate IRAEs. Recently, involvement of oligoclonal, cytotoxic, EBV-specific CD4+ memory cells in immune encephalitis in a melanoma patient receiving pembrolizumab was reported (69). The virus was expressed in lymphocytes at the encephalitic site of inflammation. Thus, it is possible that checkpoint therapy induced IREAs are caused by non-specific activation of virus- specific bystander $\mathrm{T}$ cells or by activation of virus-specific cells stimulated by reactivated virus.

\section{IMiDs, CHECKPOINT THERAPY AND MULTIPLE MYELOMA}

IMiDs such as lenalidomide, pomalidomide, and thalidomide are standard treatment for MM at various stages of the disease. They are used alone or in combination with other drugs. IMiDs target cereblon, a component of a ubiquitin ligase complex. This leads to the degradation of transcription factors IKZF1 and IKZF3 inducing myeloma cell death. IMiDs also degrade IKZF1 and IKZF3 in immune cells These transcription factors are important in $\mathrm{T}$ cell function. IKZF1 binds the IL-2 gene promoter and represses IL-2 production and proliferation in $\mathrm{T}$ cells $(70,71)$ thus controlling important steps in induction of effective immune responses, regulation of inflammation as well as prevention of autoimmunity. IMiDs also augment TCR signaling via CD28 leading to upregulation of $\mathrm{Nfkb}$ (72). T cell from MM patients who respond to lenalidomide have more IFN $\gamma$, granzyme $\mathrm{B}$ and perforin-positive $\mathrm{T}$ cells and fewer terminally differentiated $\mathrm{T}$ cells $(\mathrm{CD} 45 \mathrm{RA}+, \mathrm{CD} 57+)$ than those refractory to treatment. Furthermore, lenalidomide treatment in vitro increases proportion of myeloma antigen- specific BM T cells with a memory phenotype $(73,74)$. Interestingly, similar to what is seen in $\mathrm{T}$ cells treated with lenalidomide, $\mathrm{T}$ cells from patients with autoimmune diseases express low levels of IKZF1 (75).

Most patients respond well to IMiDs, but side effects are not uncommon. These are generally not immunological although recurrent bacterial infections due to neutropenia is a common side effect. However, a combination of IMiDs and anti-PD1 could lower the threshold of activation for memory $\mathrm{T}$ cells, anergic or tolerant $\mathrm{T}$ cells, thus leading to inflammation and organ damage. In Keynote 185, relapsed and refractory MM patients were treated with pembrolizumab, pomalidomide and dexamethasone (3) and in Keynote 183 newly diagnosed MM patients were treated with pembrolizumab, lenalidomide and dexamethasone (2). As with most of the clinical studies with anti PD1/PDL1 [Supplemental Tables 1, 2; (76)] neither studies reported positive effects, but more deaths were observed in the pembrolizumab arm. In Keynote 18519 deaths were observed in the pembrolizumab arm compared with 9 in the control with HR for OS at 2.06. In Keynote 183 there was 29 deaths in the pembrolizumab arm compared with 21 and a HR for OS of 1.61 at 8.1 month. In both studies, the incidence of serious adverse events (SAE) were higher in the pembrolizumab arm compared with control (Keynote 183 SAE 63 vs. $46 \%$, Keynote 185 AE were 54 vs. $39 \%$ ). Many of the deaths in both trials were recorded as cardio-respiratory. Indeed, one patient in Keynote 185 died of fulminant myocarditis (77). This patient did not have a previous history of heart disease or autoimmunity but developed myocarditis on day 16 post-treatment with extensive infiltration 
of Granzyme B positive CD8 T cells in the myocardium. The patient was previously treated for breast cancer with radiotherapy and this could have generated heart antigen specific $\mathrm{T}$ memory cells that were activated during treatment with pembrolizumab.

Could activation of virus-specific memory cells also lead to organ damage in the patients treated with IMiDs and checkpoint inhibitors? (as illustrated in Figure 1) Presence of CMV in cardiomyocytes are common in patients with fatal myocarditis (78), and EBV infections have occasionally been associated with myocarditis (79). Similar to solid tumors, EBV-specific PD1+ memory CD8 $\mathrm{T}$ cells are found in the bone marrow of MM patients (19) and it is reasonable to speculate that these could be activated during treatment and cause organ damage. Indeed, IMiDs can reactivate latent EBV (80) and anti-PD1 therapy can be used to promote virus clearance in animals with exhausted $\mathrm{T}$ cells (81). If this is the case, screening patients for the presence of virus-specific $\mathrm{T}$ cells and use of antivirals could prevent IREA. Thus, dissecting $\mathrm{T}$ cell responses in bio-banked samples from the clinical trials with IMiDs and anti-PD1 would be very important. Understanding the failure of response to checkpoint therapies in MM and what caused the deaths, would be very useful in developing new, efficient and safe immunotherapies for MM patients.

\section{CONCLUDING REMARKS}

$\mathrm{T}$ cells are crucial for myeloma patients, in the response to the tumor, in treatment as well as protection against common

\section{REFERENCES}

1. Mateos MV, Orlowski RZ, Ocio EM, Rodriguez-Otero P, Reece D, Moreau $\mathrm{P}$, et al. Pembrolizumab combined with lenalidomide and low-dose dexamethasone for relapsed or refractory multiple myeloma: phase I KEYNOTE-023 study. Br J Haematol. (2019) 186:e117-21. doi: 10.1111/bjh.15946

2. Mateos MV, Blacklock H, Schjesvold F, Oriol A, Simpson D, George A, et al. Pembrolizumab plus pomalidomide and dexamethasone for patients with relapsed or refractory multiple myeloma (KEYNOTE-183): a randomised, open-label, phase 3 trial. Lancet Haematol. (2019) 6:e459-69. doi: 10.1016/S2352-3026(19)30110-3

3. Usmani SZ, Schjesvold F, Oriol A, Karlin L, Cavo M, Rifkin RM, et al. Pembrolizumab plus lenalidomide and dexamethasone for patients with treatment-naive multiple myeloma (KEYNOTE-185): a randomised, open-label, phase 3 trial. Lancet Haematol. (2019) 6:e448-58. doi: 10.1016/S2352-3026(19)30 109-7

4. Guillerey C, Nakamura K, Vuckovic S, Hill GR, Smyth MJ. Immune responses in multiple myeloma: role of the natural immune surveillance and potential of immunotherapies. Cell Mol Life Sci. (2016) 73:1569-89. doi: 10.1007/s00018-016-2135-z

5. Nakamura K, Kassem S, Cleynen A, Chretien ML, Guillerey C, Putz EM, et al. Dysregulated IL-18 is a key driver of immunosuppression and a possible therapeutic target in the multiple myeloma microenvironment. Cancer Cell. (2018) 33:634-48.e635. doi: 10.1016/j.ccell.2018.02.007

6. Dhodapkar MV, Krasovsky J, Osman K, Geller MD. Vigorous premalignancy-specific effector $\mathrm{T}$ cell response in the bone marrow of patients with monoclonal gammopathy. J Exp Med. (2003) 198:1753-7. doi: $10.1084 /$ jem. 20031030 pathogens. In most adults, the $\mathrm{T}$ cell repertoire and the ability of the $\mathrm{T}$ cells to respond is shaped by what the immune system has encountered previously. Thus, to develop new types of immunotherapy, it is important to take the presence of tolerant and anergized autoimmune $\mathrm{T}$ cells as well as memory $\mathrm{T}$ cells to common pathogens into consideration. If we ignore these, we might get some unpleasant surprises.

\section{AUTHOR CONTRIBUTIONS}

AS, AW, EV, TSl, and TSt: wrote paper. AS, MB, and KM: discussed and edited wrote paper. All authors: contributed to the article and approved the submitted version.

\section{FUNDING}

This work was supported by Norwegian Cancer Society, The Research Council of Norway, The Liaison Committee for education, research and innovation in Central Norway, and the Cancer Fund at St. Olavs Hospital, Trondheim, Norway, Rakel and Otto Kr. Bruun's legacy.

\section{SUPPLEMENTARY MATERIAL}

The Supplementary Material for this article can be found online at: https://www.frontiersin.org/articles/10.3389/fimmu. 2021.636375/full\#supplementary-material
7. Zelle-Rieser C, Thangavadivel S, Biedermann R, Brunner A, Stoitzner P, Willenbacher $\mathrm{E}$, et al. $\mathrm{T}$ cells in multiple myeloma display features of exhaustion and senescence at the tumor site. J Hematol Oncol. (2016) 9:116. doi: 10.1186/s13045-016-0345-3

8. Minnie SA, Kuns RD, Gartlan KH, Zhang P, Wilkinson AN, Samson L, et al. Myeloma escape after stem cell transplantation is a consequence of T-cell exhaustion and is prevented by TIGIT blockade. Blood. (2018) 132:1675-88. doi: 10.1182/blood-2018-01-825240

9. Brown RD, Spencer A, Ho PJ, Kennedy N, Kabani K, Yang S, et al. Prognostically significant cytotoxic $\mathrm{T}$ cell clones are stimulated after thalidomide therapy in patients with multiple myeloma. Leuk Lymphoma. (2009) 50:1860-4. doi: 10.3109/10428190903216804

10. Suen H, Brown R, Yang S, Weatherburn C, Ho PJ, Woodland N, et al. Multiple myeloma causes clonal T-cell immunosenescence: identification of potential novel targets for promoting tumour immunity and implications for checkpoint blockade. Leukemia. (2016) 30:1716-24. doi: 10.1038/leu.2016.84

11. Suen H, Brown R, Yang S, Ho PJ, Gibson J, Joshua D. The failure of immune checkpoint blockade in multiple myeloma with PD-1 inhibitors in a phase 1 study. Leukemia. (2015) 29:1621-2. doi: 10.1038/leu.201 5.104

12. Puig N, Corchete-Sanchez LA, Perez-Moran JJ, Davila J, Paino T, de la Rubia $\mathrm{J}$, et al. Pembrolizumab as consolidation strategy in patients with multiple myeloma: results of the GEM-pembresid clinical trial. Cancers (Basel). (2020) 12:3615. doi: $10.3390 /$ cancers 12123615

13. Feyler S, von Lilienfeld-Toal M, Jarmin S, Marles L, Rawstron A, Ashcroft $\mathrm{AJ}$, et al. $\mathrm{CD} 4(+) \mathrm{CD} 25(+) \mathrm{FoxP} 3(+)$ regulatory $\mathrm{T}$ cells are increased whilst CD3(+)CD4(-)CD8(-)alphabetaTCR(+) Double Negative T cells are decreased in the peripheral blood of patients with multiple myeloma which correlates with disease burden. Br J Haematol. (2009) 144:686-95. doi: 10.1111/j.1365-2141.2008.07530.x 
14. Kawano Y, Zavidij O, Park J, Moschetta M, Kokubun K, Mouhieddine TH, et al. Blocking IFNAR1 inhibits multiple myeloma-driven Treg expansion and immunosuppression. J Clin Invest. (2018) 128:2487-99. doi: 10.1172/JCI88169

15. Alrasheed N, Lee L, Ghorani E, Henry JY, Conde L, Chin M, et al. Marrow-infiltrating regulatory $\mathrm{T}$ cells correlate with the presence of dysfunctional CD4(+)PD-1(+) cells and inferior survival in patients with newly diagnosed multiple myeloma. Clin Cancer Res. (2020) 26:3443-54. doi: 10.1158/1078-0432.CCR-19-1714

16. Dhodapkar KM, Barbuto S, Matthews P, Kukreja A, Mazumder A, Vesole D, et al. Dendritic cells mediate the induction of polyfunctional human IL17producing cells (Th17-1 cells) enriched in the bone marrow of patients with myeloma. Blood. (2008) 112:2878-85. doi: 10.1182/blood-2008-03-143222

17. Bailur JK, McCachren SS, Doxie DB, Shrestha M, Pendleton K, Nooka AK, et al. Early alterations in stem-like/resident T cells, innate and myeloid cells in the bone marrow in preneoplastic gammopathy. JCI Insight. (2019) 5:e127807. doi: 10.1172/jci.insight.127807

18. Zavidij O, Haradhvala NJ, Mouhieddine TH, Sklavenitis-Pistofidis R, Cai S, Reidy $\mathrm{M}$, et al. Single-cell RNA sequencing reveals compromised immune microenvironment in precursor stages of multiple myeloma. Nat Cancer. (2020) 1:493-506. doi: 10.1038/s43018-020-0053-3

19. Sponaas AM, Yang R, Rustad EH, Standal T, Thoresen AS, Dao Vo C, et al. PD1 is expressed on exhausted $\mathrm{T}$ cells as well as virus specific memory CD8 + T cells in the bone marrow of myeloma patients. Oncotarget. (2018) 9:32024-35. doi: 10.18632/oncotarget.25882

20. Zahoor M, Westhrin M, Aass KR, Moen SH, Misund K, Psonka-Antonczyk $\mathrm{KM}$, et al. Hypoxia promotes IL-32 expression in myeloma cells, and high expression is associated with poor survival and bone loss. Blood Adv. (2017) 1:2656-66. doi: 10.1182/bloodadvances.2017010801

21. Borset M, Sundan A, Waage A, Standal T. Why do myeloma patients have bone disease? A historical perspective. Blood Rev. (2020) 41:100646. doi: 10.1016/j.blre.2019.100646

22. Westhrin M, Kovcic V, Zhang Z, Moen SH, Nedal TMV, Bondt A, et al. Monoclonal immunoglobulins promote bone loss in multiple myeloma. Blood. (2020) 136:2656-66. doi: 10.1182/blood.2020006045

23. Blimark C, Holmberg E, Mellqvist UH, Landgren O, Björkholm M, Hultcrantz $\mathrm{M}$, et al. Multiple myeloma and infections: a population-based study on 9253 multiple myeloma patients. Haematologica. (2015) 100:107-13. doi: 10.3324/haematol.2014.107714

24. Lorenza Torti AM, Bacci F, Di Bartolomeo P. Infections and immune system impairment in multiple myeloma: increasing frequency of serious complications in the "Novel Agents Era” -A retrospective real life analysis. Blood. (2017) 130: 1875. doi: 10.1182/blood.V130.Suppl_1.1875.1875

25. Vuckovic S, Bryant CE, Lau KHA, Yang S, Favaloro J, McGuire HM, et al. Inverse relationship between oligoclonal expanded CD69- TTE and CD69+ TTE cells in bone marrow of multiple myeloma patients. Blood Adv. (2020) 4:4593-604. doi: 10.1182/bloodadvances.2020002237

26. Goodyear O, Piper K, Khan N, Starczynski J, Mahendra P, Pratt G, et al. CD8+ $\mathrm{T}$ cells specific for cancer germline gene antigens are found in many patients with multiple myeloma, and their frequency correlates with disease burden. Blood. (2005) 106:4217-24. doi: 10.1182/blood-2005-02-0563

27. van Rhee F, Szmania SM, Zhan F, Gupta SK, Pomtree M, Lin P, et al. NY-ESO-1 is highly expressed in poor-prognosis multiple myeloma and induces spontaneous humoral and cellular immune responses. Blood. (2005) 105:3939-44. doi: 10.1182/blood-2004-09-3707

28. Qian J, Xie J, Hong S, Yang J, Zhang L, Han X, et al. Dickkopf-1 (DKK1) is a widely expressed and potent tumor-associated antigen in multiple myeloma. Blood. (2007) 110:1587-94. doi: 10.1182/blood-2007-03-082529

29. Perumal D, Imai N, Lagana A, Finnigan J, Melnekoff D, Leshchenko VV, et al. Mutation-derived Neoantigen-specific T-cell Responses in Multiple Myeloma. Clin Cancer Res. (2020) 26:450-64. doi: 10.1158/1078-0432.CCR-19-2309

30. Simoni Y, Becht E, Fehlings M, Loh CY, Koo SL, Teng KWW, et al. Bystander CD8(+) T cells are abundant and phenotypically distinct in human tumour infiltrates. Nature. (2018) 557:575-9. doi: 10.1038/s41586-018-0130-2

31. Okhrimenko A, Grun JR, Westendorf K, Fang Z, Reinke S, von Roth P, et al. Human memory $\mathrm{T}$ cells from the bone marrow are resting and maintain long-lasting systemic memory. Proc Natl Acad Sci USA. (2014) 111:9229-34. doi: $10.1073 /$ pnas.1318731111
32. Kovtonyuk LV, Fritsch K, Feng $\mathrm{X}$, Manz MG, Takizawa $H$. Inflamm-aging of hematopoiesis, hematopoietic stem cells, and the bone marrow microenvironment. Front Immunol. (2016) 7:502. doi: 10.3389/fimmu.2016.00502

33. Long HM, Meckiff BJ, Taylor GS. The T-cell response to epstein-barr virus-new tricks from an old dog. Front Immunol. (2019) 10:2193. doi: 10.3389/fimmu.2019.02193

34. Forte E, Zhang Z, Thorp EB, Hummel M. Cytomegalovirus latency and reactivation: an intricate interplay with the host immune response. Front Cell Infect Microbiol. (2020) 10:130. doi: 10.3389/fcimb.2020.00130

35. Appay V, Rowland-Jones SL. Lessons from the study of T-cell differentiation in persistent human virus infection. Semin Immunol. (2004) 16:205-12. doi: 10.1016/j.smim.2004.02.007

36. Fulop T, Larbi A, Pawelec G. Human T cell aging and the impact of persistent viral infections. Front Immunol. (2013) 4:271. doi: 10.3389/fimmu.2013.00271

37. Cox B, Richardson A, Graham P, Gislefoss RE, Jellum E, Rollag H. Breast cancer, cytomegalovirus and Epstein-Barr virus: a nested case-control study. Br J Cancer. (2010) 102:1665-9. doi: 10.1038/sj.bjc.6605675

38. Massoud R, Assi R, Fares E, Haffar B, Charafeddine M, Kreidieh N, et al. Cytomegalovirus reactivation in lymphoma and myeloma patients undergoing autologous peripheral blood stem cell transplantation. J Clin Virol. (2017) 95:36-41. doi: 10.1016/j.jcv.2017.08.006

39. Abbott RJ, Quinn LL, Leese AM, Scholes HM, Pachnio A, Rickinson AB. $\mathrm{CD} 8+\mathrm{T}$ cell responses to lytic EBV infection: late antigen specificities as subdominant components of the total response. J Immunol. (2013) 191:5398409. doi: 10.4049/jimmunol.1301629

40. Hislop AD, Taylor GS. T-cell responses to EBV. Curr Top Microbiol Immunol. (2015) 391:325-53. doi: 10.1007/978-3-319-22834-1_11

41. Taylor GS, Long HM, Brooks JM, Rickinson AB, Hislop AD. The immunology of Epstein-Barr virus-induced disease. Annu Rev Immunol. (2015) 33:787821. doi: 10.1146/annurev-immunol-032414-112326

42. Britanova OV, Shugay M, Merzlyak EM, Staroverov DB, Putintseva EV, Turchaninova MA, et al. Dynamics of individual $\mathrm{T}$ cell repertoires: from cord blood to centenarians. J Immunol. (2016) 196:5005-13. doi: 10.4049/jimmunol.1600005

43. Klarenbeek PL, Remmerswaal EB, ten Berge IJ, Doorenspleet ME, van Schaik $\mathrm{BD}$, Esveldt RE, et al. Deep sequencing of antiviral T-cell responses to $\mathrm{HCMV}$ and EBV in humans reveals a stable repertoire that is maintained for many years. PLoS Pathog. (2012) 8:e1002889. doi: 10.1371/journal.ppat.10 02889

44. Casorati G, Locatelli F, Pagani S, Garavaglia C, Montini E, Lisini D, et al. Bone marrow-resident memory $\mathrm{T}$ cells survive pretransplant chemotherapy and contribute to early immune reconstitution of patients with acute myeloid leukemia given mafosfamide-purged autologous bone marrow transplantation. Exp Hematol. (2005) 33:212-8. doi: 10.1016/j.exphem.2004.10.008

45. Roberto A, Castagna L, Zanon V, Bramanti S, Crocchiolo R, McLaren JE, et al. Role of naive-derived $\mathrm{T}$ memory stem cells in T-cell reconstitution following allogeneic transplantation. Blood. (2015) 125:2855-64. doi: 10.1182/blood-2014-11-608406

46. Inazawa N, Hori T, Nojima M, Saito M, Igarashi K, Yamamoto M, et al. Virus reactivations after autologous hematopoietic stem cell transplantation detected by multiplex PCR assay. J Med Virol. (2017) 89:358-62. doi: $10.1002 /$ jmv.24621

47. Rosato PC, Wijeyesinghe S, Stolley JM, Nelson CE, Davis RL, Manlove LS, et al. Virus-specific memory $\mathrm{T}$ cells populate tumors and can be repurposed for tumor immunotherapy. Nat Commun. (2019) 10:567. doi: 10.1038/s41467-019-08534-1

48. Yang R, Elsaadi S, Misund K, Abdollahi P, Vandsemb EN, Moen SH, et al. Conversion of ATP to adenosine by CD39 and CD73 in multiple myeloma can be successfully targeted together with adenosine receptor A2A blockade. $J$ Immunother Cancer. (2020) 8:e006610. doi: 10.1136/jitc-2020-000610

49. Gross DM, Forsthuber T, Tary-Lehmann M, Etling C, Ito K, Nagy ZA, et al. Identification of LFA-1 as a candidate autoantigen in treatment-resistant Lyme arthritis. Science. (1998) 281:703-6. doi: 10.1126/science.281.53 77.703

50. Cunningham MW. T cell mimicry in inflammatory heart disease. Mol Immunol. (2004) 40:1121-7. doi: 10.1016/j.molimm.2003.11.023 
51. McCoy L, Tsunoda I, Fujinami RS. Multiple sclerosis and virus induced immune responses: autoimmunity can be primed by molecular mimicry and augmented by bystander activation. Autoimmunity. (2006) 39:9-19. doi: 10.1080/089169305004 84799

52. Padovan E, Casorati G, Dellabona P, Meyer S, Brockhaus M, Lanzavecchia A. Expression of two T cell receptor alpha chains: dual receptor T cells. Science. (1993) 262:422-4. doi: 10.1126/science.8211163

53. Whiteside SK, Snook JP, Williams MA, Weis JJ. Bystander T cells: a balancing act of friends and foes. Trends Immunol. (2018) 39:1021-35. doi: 10.1016/j.it.2018.10.003

54. Levy R, Rotfogel Z, Hillman D, Popugailo A, Arad G, Supper E, et al. Superantigens hyperinduce inflammatory cytokines by enhancing the B72/CD28 costimulatory receptor interaction. Proc Natl Acad Sci USA. (2016) 113:E6437-46. doi: 10.1073/pnas.1603321113

55. Kabelitz D. Expression and function of Toll-like receptors in T lymphocytes. Curr Opin Immunol. (2007) 19:39-45. doi: 10.1016/j.coi.2006.11.007

56. Komai-Koma M, Jones L, Ogg GS, Xu D, Liew FY. TLR2 is expressed on activated T cells as a costimulatory receptor. Proc Natl Acad Sci USA. (2004) 101:3029-34. doi: 10.1073/pnas.0400171101

57. Reynolds JM, Dong C. Toll-like receptor regulation of effector T lymphocyte function. Trends Immunol. (2013) 34:511-9. doi: 10.1016/j.it.2013.06.003

58. Tietze JK, Wilkins DE, Sckisel GD, Bouchlaka MN, Alderson KL, Weiss $\mathrm{JM}$, et al. Delineation of antigen-specific and antigen-nonspecific CD8(+) memory T-cell responses after cytokine-based cancer immunotherapy. Blood. (2012) 119:3073-83. doi: 10.1182/blood-2011-07-369736

59. Dhanji S, Teh HS. IL-2-activated CD8+CD44high cells express both adaptive and innate immune system receptors and demonstrate specificity for syngeneic tumor cells. J Immunol. (2003) 171:3442-50. doi: 10.4049/jimmunol.171.7.3442

60. Meresse B, Chen Z, Ciszewski C, Tretiakova M, Bhagat G, Krausz TN, et al. Coordinated induction by IL15 of a TCR-independent NKG2D signaling pathway converts CTL into lymphokine-activated killer cells in celiac disease. Immunity. (2004) 21:357-66. doi: 10.1016/j.immuni.2004.06.020

61. Maasho K, Opoku-Anane J, Marusina AI, Coligan JE, Borrego F. NKG2D is a costimulatory receptor for human naive CD8+ T cells. J Immunol. (2005) 174:4480-4. doi: 10.4049/jimmunol.174.8.4480

62. Weng NP, Araki Y, Subedi K. The molecular basis of the memory T cell response: differential gene expression and its epigenetic regulation. Nat Rev Immunol. (2012) 12:306-15. doi: 10.1038/nri3173

63. Wu TD, Madireddi S, de Almeida PE, Banchereau R, Chen YJ, Chitre AS, et al. Peripheral $\mathrm{T}$ cell expansion predicts tumour infiltration and clinical response. Nature. (2020) 579:274-8. doi: 10.1038/s41586-020-2056-8

64. Sade-Feldman M, Yizhak K, Bjorgaard SL, Ray JP, de Boer CG, Jenkins RW, et al. Defining $\mathrm{T}$ cell states associated with response to checkpoint immunotherapy in melanoma. Cell. (2018) 175:998-1013.e1020. doi: 10.1016/j.cell.2018.10.038

65. Salem JE, Manouchehri A, Moey M, Lebrun-Vignes B, Bastarache L, Pariente A, et al. Cardiovascular toxicities associated with immune checkpoint inhibitors: an observational, retrospective, pharmacovigilance study. Lancet Oncol. (2018) 19:1579-89. doi: 10.1016/S1470-2045(18)30608-9

66. Ganatra S, Neilan TG. Immune checkpoint inhibitor-associated myocarditis. Oncologist. (2018) 23:879-86. doi: 10.1634/theoncologist.2018-0130

67. Okazaki T, Honjo T. The PD-1-PD-L pathway in immunological tolerance. Trends Immunol. (2006) 27:195-201. doi: 10.1016/j.it.2006.02.001

68. Keir ME, Butte MJ, Freeman GJ, Sharpe AH. PD-1 and its ligands in tolerance and immunity. Annu Rev Immunol. (2008) 26:677-704. doi: 10.1146/annurev.immunol.26.021607.090331
69. Johnson DB, McDonnell WJ, Gonzalez-Ericsson PI, Al-Rohil RN, Mobley BC, Salem JE, et al. A case report of clonal EBV-like memory CD4(+) T cell activation in fatal checkpoint inhibitor-induced encephalitis. Nat Med. (2019) 25:1243-50. doi: 10.1038/s41591-019-0523-2

70. Kortum KM, Zhu YX, Shi CX, Jedlowski P, Stewart AK. Cereblon binding molecules in multiple myeloma. Blood Rev. (2015) 29:329-34. doi: 10.1016/j.blre.2015.03.003

71. Sehgal K, Das R, Zhang L, Verma R, Deng Y, Kocoglu M, et al. Clinical and pharmacodynamic analysis of pomalidomide dosing strategies in myeloma: impact of immune activation and cereblon targets. Blood. (2015) 125:4042-51. doi: 10.1182/blood-2014-11-611426

72. LeBlanc R, Hideshima T, Catley LP, Shringarpure R, Burger R, Mitsiades N, et al. Immunomodulatory drug costimulates T cells via the B7-CD28 pathway. Blood. (2004) 103:1787-90. doi: 10.1182/blood-2003-02-0361

73. Haslett PA, Corral LG, Albert M, Kaplan G. Thalidomide costimulates primary human $\mathrm{T}$ lymphocytes, preferentially inducing proliferation, cytokine production, and cytotoxic responses in the CD8+ subset. J Exp Med. (1998) 187:1885-92. doi: 10.1084/jem.187.11.1885

74. Kramer I, Engelhardt M, Fichtner S, Neuber B, Medenhoff S, Bertsch U, et al. Lenalidomide enhances myeloma-specific T-cell responses in vivo and in vitro. Oncoimmunology. (2016) 5:e1139662. doi: 10.1080/2162402X.2016.1139662

75. McKinney EF, Lee JC, Jayne DR, Lyons PA, Smith KG. T-cell exhaustion, co-stimulation and clinical outcome in autoimmunity and infection. Nature. (2015) 523:612-6. doi: 10.1038/nature14468

76. Jelinek T, Paiva B, Hajek R. Update on PD-1/PD-L1 inhibitors in multiple myeloma. Front Immunol. (2018) 9:2431. doi: 10.3389/fimmu.2018.02431

77. Martinez-Calle N, Rodriguez-Otero P, Villar S, Mejias L, Melero I, Prosper F, et al. Anti-PD1 associated fulminant myocarditis after a single pembrolizumab dose: the role of occult pre-existing autoimmunity. Haematologica. (2018) 103:e318-21. doi: 10.3324/haematol.2017.185777

78. Kyto V, Vuorinen T, Saukko P, Lautenschlager I, Lignitz E, Saraste $\mathrm{A}$, et al. Cytomegalovirus infection of the heart is common in patients with fatal myocarditis. Clin Infect Dis. (2005) 40:683-8. doi: 10.1086/427804

79. Mutlu H, Alam M, Ozbilgin OF. A rare case of Epstein-Barr virusinduced dilated cardiomyopathy. Heart Lung. (2011) 40:81-7. doi: 10.1016/j.hrtlng.2009.12.012

80. Jones RJ, Iempridee $\mathrm{T}$, Wang $\mathrm{X}$, Lee HC, Mertz JE, Kenney SC, et al. Lenalidomide, thalidomide, and pomalidomide reactivate the Epstein-Barr virus lytic cycle through phosphoinositide 3-kinase signaling and ikaros expression. Clin Cancer Res. (2016) 22:4901-12. doi: 10.1158/1078-0432.CCR-15-2242

81. Barber DL, Wherry EJ, Masopust D, Zhu B, Allison JP, Sharpe AH, et al. Restoring function in exhausted CD8 T cells during chronic viral infection. Nature. (2006) 439:682-7. doi: $10.1038 /$ nature 04444

Conflict of Interest: The authors declare that the research was conducted in the absence of any commercial or financial relationships that could be construed as a potential conflict of interest.

Copyright (c) 2021 Sponaas, Waage, Vandsemb, Misund, Børset, Sundan, Slørdahl and Standal. This is an open-access article distributed under the terms of the Creative Commons Attribution License (CC BY). The use, distribution or reproduction in other forums is permitted, provided the original author(s) and the copyright owner(s) are credited and that the original publication in this journal is cited, in accordance with accepted academic practice. No use, distribution or reproduction is permitted which does not comply with these terms. 